\title{
Verification of MPG Illusion When Fuel Efficiency Is Expressed by $\mathrm{km} / 1$
}

\author{
Atsuo Murata \\ Okayama University, Okayama, Japan
}

\begin{abstract}
We conducted three questionnaire surveys to test whether people are get trapped in MPG illusion and falsely reason the reduction in gas consumption on the basis of the linear relationship between fuel efficiency and reduction in gas consumption. The MPG illusion corresponds to a cognitive bias in judging fuel efficiency when it is expressed as miles per gallon used in US. We misunderstand that the amount of gas consumed by an automobile decreases as a linear function of automobile's MPG, although the actual relationship is curvilinear. We made an attempt to confirm whether this illusion is also true for Japanese people, and it was investigated whether cross cultural difference exists in the MPG illusion (km per liter was used instead of MPG, because Japanese people are generally accustomed to not MPG but km per liter). The following findings were obtained as a result of three questionnaire surveys. The participants misunderstood that the larger change of $\mathrm{km} / \mathrm{l}$ linearly led to the larger reduction in gas consumption, although the relationship is actually curvilinear. The MPG illusion was observed for both US and Japanese people, and no cross cultural difference was detected concerning this type of cognitive bias. The MPG illusion (bias) was effectively removed by replacing distance-over-volume measures such as $\mathrm{km} / \mathrm{l}$ or MPG by volume-over-distance measures such as $1 / \mathrm{km}$ or GPM.
\end{abstract}

Keywords: cross-cultural difference, cognitive bias, MPG, km/1, 1/km, debiasing

\section{Introduction}

Although we must make decision rationally without suffering from cognitive biases, it is difficult for us to make decision rationally and without being affected by cognitive biases (Kahneman, 2011; Tversky \& Kahneman, 1974; Kahneman \& Tversky, 1984; Altman, 2012; Anger, 2012; Bazerman \& Moore, 2001; Murata, Nakamura, \& Karwowski, 2015). Our thinking is ruled by bounded rationality, and cognitive information processing is based on either System1 or System2. System1 is simple and intuitive, operates quickly, automatically, without time consuming, and intuitively with little or no efforts. System 2 requires us to conduct effortful, demanding and deliberate mental activities. When we have no time to deliberate, we tend to adopt heuristic approaches based on System1. The processing by System1 frequently suffers from cognitive biases.

Bazerman and Moore (2001) hypothesized that availability, representativeness, confirmation, or affect heuristics form the basis of a variety of biases such as availability bias, confirmation bias, hindsight bias, ignorance of base rate, conjunction fallacy, ignorance of sample size, and anchoring and adjustment. They also insisted that not only heuristics but also overconfidence and framing presumably cause a variety of biases.

Atsuo Murata, Ph.D., professor, Department of Intelligent Mechanical Systems, Graduate School of Natural Science and Technology, Okayama University. 
Moreover, they assumed that our bounded awareness and uncertain situations form the basis of heuristics, overconfidence, and framing. Based on such discussion, it seems valid to judge that we sometimes can behave irrationally. In this manner, we at times show a tendency of irrational behavior. In most cases, we tend to be unaware of how irrational behaviors affect us. Such irrational properties unconsciously distort our decisions and, in the worst case, lead to undesirable events or outcomes such as incidents, collisions, disasters, or crashes as pointed out by Murata et al. (2015). Dobelli (2013) summarized 99 cognitive biases, and stated that we must recognize cognitive biases and evade them in our thinking, although cognitive biases are too engrained to rid ourselves of them completely.

Larrick and Soll (2008) reported the miles per gallon (MPG) illusion. When purchasing a car, many people consider fuel efficiency, and try to reduce gas consumption and eventually a gasoline bill. In order to reduce gas consumption, we must accurately understand what fuel efficiency such as MPG or km/l means. Larrick and Soll (2008) found that a cognitive bias occurs when judging fuel efficiency using MPG. The participants tended to misunderstand that the amount of gas consumed by an automobile decreases as a linear function of MPG, although the actual relationship is not linear but curvilinear.

We conducted three questionnaire surveys to test whether people reason in a linear, but incorrect (cognitively biased), fashion about gas consumption in a similar manner to Larrick and Soll (2008) even for fuel efficiency measure of $\mathrm{km} / \mathrm{l}$ which is traditionally used in Japan. The MPG illusion corresponds to a cognitive bias in which we falsely tend to think that the amount of gas consumed by an automobile decreases as a linear function of automobile's MPG, although the actual relationship is curvilinear. In this study, an attempt was made to confirm whether this illusion is also true for Japanese participants who are accustomed to use $\mathrm{km} / 1$ expression as fuel efficiency, and it was investigated whether cross cultural difference existed in the MPG illusion ( $\mathrm{km}$ per liter was used instead of MPG).

\section{Method}

\section{Participants}

Sixty-six undergraduate students aged from 20 to 25 years old at Faculty of Engineering, Okayama University agreed to answer the three questionnaires below.

\section{Task and Procedure}

The following three types of questionnaires were used. The unit (MPG) in Study1-Study3 conducted by Larrick and Soll (2008) was transformed to $\mathrm{km} / \mathrm{l}$, because Japanese people generally are not accustomed to the unit MPG. The same value with Larrick and Soll (2008) was used to compare the results between this study and theirs.

Questionnaire1-Rank of reduction in gas consumption. The participants were required to assume that a driver drives $16,090 \mathrm{~km}$ per year (10,000 miles per year), and is planning to change from a current vehicle to a new one. The change of $\mathrm{km} / \mathrm{l}$ (MPG) from a current vehicle to a new one had the following patterns from (A) to (E): (A) $14.5 \mathrm{~km} / 1$ (34 MPG) (current vehicle) to $21.3 \mathrm{~km} / 1$ (50 MPG) (new vehicle), (B) $7.7 \mathrm{~km} / 1$ (18MPG) to $11.9 \mathrm{~km} / 1$ (28 MPG), (C) $17.9 \mathrm{~km} / 1$ (42 MPG) to $20.4 \mathrm{~km} / 1$ (48 MPG), (D) $6.8 \mathrm{~km} / 1$ (16 MPG) to $8.5 \mathrm{~km} / 1$ (20 MPG), and (E) $9.4 \mathrm{~km} / 1$ (22 MPG) to $10.2 \mathrm{~km} / 1$ (24 MPG). The participants were required to intuitively rank in gas savings for the patterns (A)-(E). In other words, the participants were required to evaluate which new vehicle from (A)-(E) would reduce gas consumption the most compared to the current one using a number 
between 1 for the most beneficial change and 5 for the least beneficial change.

Questionnaire2-Relationship between fuel efficiency and WTP. The participants were required to assume that a driver drives $16,090 \mathrm{~km}$ per year (10,000 miles per year), and the fuel efficiency of your current vehicle, the price of which is $2,180,000$ yen $(\$ 20,000)$, is $6.4 \mathrm{~km} / 1$ (15 MPG). The participants were required to describe the highest price they would be willing to pay for the vehicles that differed only in fuel efficiency as follows: $7.7 \mathrm{~km} / 1$ (19 MPG), $10.6 \mathrm{~km} / 1$ (25 MPG), $14.0 \mathrm{~km} / 1$ (32.5 MPG), $17.9 \mathrm{~km} / 1$ (43.5 MPG), and $23.4 \mathrm{~km} / 1$ (55 MPG).

Questionnaire3 - Comparison of percentage correct choice between $\mathbf{k m} / \mathbf{l}$ and $\mathbf{~} / \mathbf{k m}$ representation. A total of 66 participants were equally allocated to Prblem3-1 (33 participants) and Problem3-2 (33 participants).

Problem3-1. Participants were indicated to assume that a town has two types of vehicles A and B. The fuel efficiency of Types A and B were $6.4 \mathrm{~km} / 1$ (15 MPG) and $14.5 \mathrm{~km} / 1$ (34 MPG), respectively. The town has 100 Type A and 100 Type B vehicles, and each car is driven 16,090 km (10,000 miles) annually. Participants were asked to intuitively choose between the following two options from the viewpoints of reduction in gas consumption.

Option1: simultaneously replace the 100 Type A vehicles with vehicles that have $8.1 \mathrm{~km} / 1$ (19 MPG).

Option2: simultaneously replace the 100 Type B vehicles with vehicles that have $18.7 \mathrm{~km} / 1$ (44 MPG).

Problem3-2. Participants were indicated to assume that a town has two types of vehicles A and B. Types A and B have $6.4 \mathrm{~km} / 1$ (15 MPG) and $14.5 \mathrm{~km} / 1$ (34 MPG), respectively. The town has 100 Type A and 100 Type B vehicles, and each car is driven 16,090 km (10,000 miles) annually. The difference from Problem3-1 is that the fuel efficiency was expressed in terms of $1 / \mathrm{km}$ (gallons per 100 miles) instead of $\mathrm{km} / \mathrm{l}$ (MPG). Participants were asked to intuitively choose between the following two options from the viewpoints of reduction in gas consumption.

Option1: simultaneously replace the 100 type A vehicles $(0.16 \mathrm{l} / \mathrm{km}(6.67$ gallons $/ 100$ miles $))$ with vehicles $C$ that have $0.121 / \mathrm{km}$ (5.25 gallons $/ 100$ miles).

Option2: simultaneously replace the 100 type B vehicles $(0.07 \mathrm{l} / \mathrm{km}(2.94$ gallons $/ 100$ miles $))$ with vehicles $\mathrm{D}$ that have $0.051 / \mathrm{km}$ (2.27 gallons/100 miles).

\section{Results}

\section{Questionnaire1-Rank of Reduction in Gas Consumption}

The perceived mean rank was as follows: 34 MPG to 50 MPG (1.18), 18 MPG to 28 MPG (1.95), 42 MPG to $48 \mathrm{MPG}$ (3.29), $16 \mathrm{MPG}$ to $20 \mathrm{MPG}$ (3.73), and $22 \mathrm{MPG}$ to 24 MPG (4.86). The actual rank of Questionnaire1 was as follows: 18 MPG to 28 MPG (actual rank: 1), 16 MPG to 20 MPG (actual rank: 2), 34 MPG to 50 MPG (actual rank: 3), 22 MPG to 24 MPG (actual rank: 4), and 42 MPG to 48 MPG (actual rank: 5). The results are summarized in Table 1.

\section{Questionnaire2-Relationship between Fuel Efficiency and WTP}

As well as the results in 3.1, mean WTP in this study and Larrick and Soll (2008) showed a clear linear relationship with km/l or MPG (see Figure 1) due to the participants' misunderstanding that the increase of fuel efficiency directly leads to the reduction in gas consumption. Participants gave mean WTP values that, compared with expected gas savings, underestimated the improvements of $7.7 \mathrm{~km} / 1$ (19 MPG), $10.6 \mathrm{~km} / 1$ ( 25 MPG), and $14.9 \mathrm{~km} / 1$ (32.5 MPG) and overestimated the improvement of $17.9 \mathrm{~km} / 1$ (43.5 MPG), and $23.4 \mathrm{~km} / 1$ 
(55 MPG). It must be also noted that WTP in this study was smaller that that in Larrick and Soll (2008), although WTP increased linearly as a function of fuel efficiency.

\section{Questionnaire3 - Comparison of Percentage Correct Choice between $\mathbf{k m} / \mathbf{l}$ and $1 / \mathbf{k m}$ Representation}

The percentages of choice of Option1 and Option2 in Questionnaire3-1 and Questionnaire3-2 are shown in Figure 2. The percentages of choice in Questionnaire3-1 were $42 \%$ and $58 \%$ in Option 1 and Optiona2, respectively. The percentages of choice in Questionnaire3-2 were 61\% and 39\% in Option1 and Option2, respectively. The choice of Prblem3-1 was reversed in Questionnaire3-2. Option1 is a theoretically correct one. The results show that the expression using $1 / \mathrm{km}$ or GPM readily leads to a correct option. These results were also similar to Larrick and Soll (2008).

Table 1

Mean Rank in Gas Saving, Actual Rank in Gas Saving, and Actual Reduction in Gas Consumption per 16,090 $\mathrm{km}$ (Problem1)

\begin{tabular}{lllll}
\hline \multirow{2}{*}{$\begin{array}{l}\text { Fuel efficiency current to } \\
\text { vehicle to new one }\end{array}$} & This study & Mean rank & $\begin{array}{l}\text { Actual rank in gas } \\
\text { saving }\end{array}$ & $\begin{array}{l}\text { Actual reduction in gas } \\
\text { consumption per 16,090 } \\
\text { km }(10,000 \text { miles })\end{array}$ \\
\hline $\begin{array}{l}14.5 \mathrm{~km} / 1 \rightarrow 21.3 \mathrm{~km} / 1 \\
(34 \mathrm{MPG} \rightarrow 50 \mathrm{MPG})\end{array}$ & 1.20 & 1.18 & 3 & 352.31 (94.1 gallons) \\
$\begin{array}{l}7.7 \mathrm{~km} / 1 \rightarrow 11.9 \mathrm{~km} / 1 \\
(18 \mathrm{MPG} \rightarrow 28 \mathrm{MPG})\end{array}$ & 2.14 & 1.95 & 1 & $733.41(198.4$ gallons $)$ \\
$\begin{array}{l}17.9 \mathrm{~km} / \mathrm{l} \rightarrow 20.4 \mathrm{~km} / 1 \\
(42 \mathrm{MPG} \rightarrow 48 \mathrm{MPG})\end{array}$ & 3.00 & 3.29 & 5 & $109.51(29.8$ gallons $)$ \\
$\begin{array}{l}6.8 \mathrm{~km} / 1 \rightarrow 8.5 \mathrm{~km} / 1 \\
(16 \mathrm{MPG} \rightarrow 20 \mathrm{MPG})\end{array}$ & 3.92 & 3.73 & 2 & $470.61(125.0$ gallons $)$ \\
$\begin{array}{l}9.4 \mathrm{~km} / 1 \rightarrow 10.2 \mathrm{~km} / 1 \\
(22 \mathrm{MPG} \rightarrow 24 \mathrm{MPG})\end{array}$ & 4.74 & 4.86 & 4 & $133.51(37.9$ gallons $)$ \\
\hline
\end{tabular}

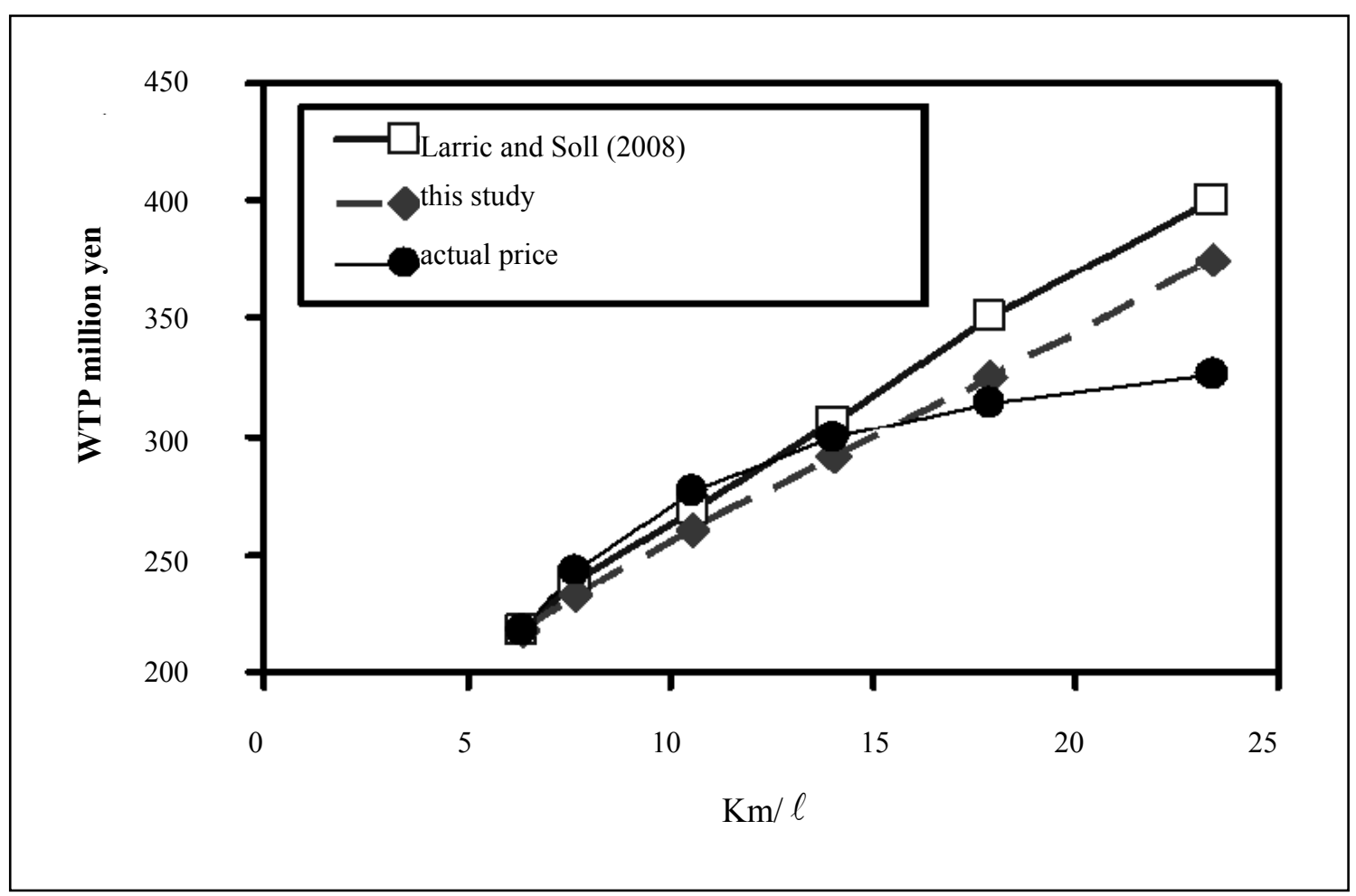

Figure 1. Relationship between fuel efficiency and WTP (Problem2). 


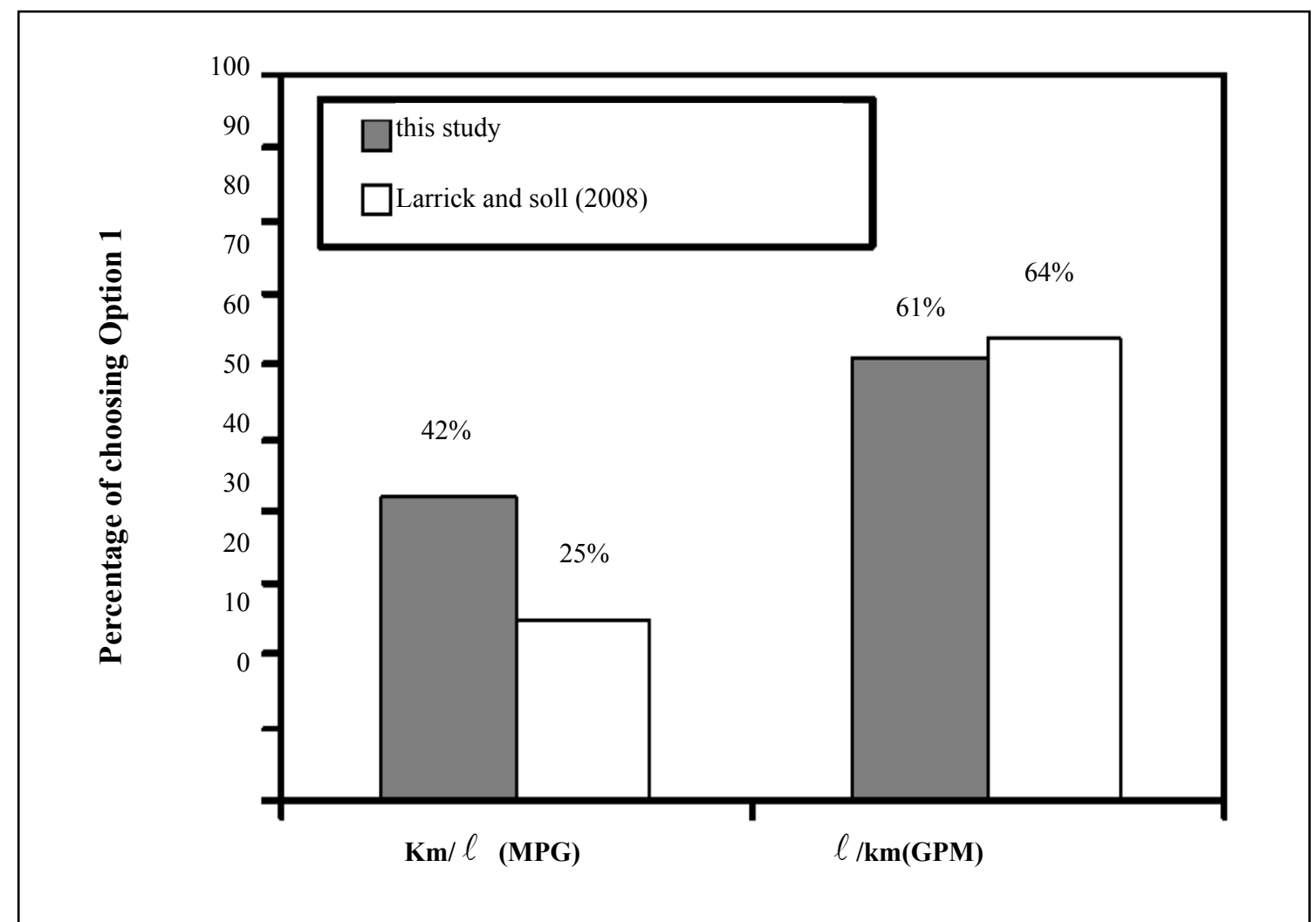

Figure 2. Comparison of percentage of choosing Option1 between $\mathrm{km} / \mathrm{l}$ and $1 / \mathrm{km}$ representations and between this study and Larrick and Soll (2008) (Problem3).

\section{Discussion}

\section{Questionnaire1-Rank of Reduction in Gas Consumption}

As shown in Table 1, the participants tend to misunderstand that the larger change in $\mathrm{km} / \mathrm{l}$ linearly led to the larger reduction in gas consumption. In other words, the participants in both Larrick and Soll (2008) and this study perceived that the larger change in fuel efficiency ( $\mathrm{km} / \mathrm{l}$ or MPG) led to the improvement in actual reduction in gas consumption. Only $1 \%$ and $1.5 \%$ of the participants ranked according to actual improvement in gas consumption in Larrick and Soll (2008) and this study, respectively. For both cases of MPG and km/l, the participants got trapped in the MPG illusion. As in Table 1, the rank of reduction in gas consumption of this study was nearly equal to that in Larrick and Soll (2008). The results indicates that using $\mathrm{km} / \mathrm{l}$ or MPG is misunderstood as representing environmental protection such as reduction in gas consumption.

\section{Questionnaire2-Relationship between Fuel Efficiency and WTP}

Mean willingness to pay (WTP) showed a clear linear relationship with MPG improvement for both this study and Larrick and Soll (2008) (see Figure 1). The majority of participants assumed that there was a linear relationship between the $\mathrm{km} / \mathrm{l}$ (MPG) improvement and WTP, although the relationship was actually nonlinear as shown in Figure 1. As a matter of fact, participants gave mean WTP values that, compared with expected gas savings expressed as vehicle price, underestimated the improvements of $7.7 \mathrm{~km} / 1$ (19 MPG), $10.6 \mathrm{~km} / 1$ (25 MPG), and $14.9 \mathrm{~km} / 1$ (32.5 MPG) and overestimated the improvement of $17.9 \mathrm{~km} / 1$ (43.5 MPG), and $23.4 \mathrm{~km} / 1$ (55 MPG). 
Comparing the difference of WTP and actual price among the conditions of fuel efficiency revealed the following results. While the smallest difference was $-171,000$ yen (actual price and WTP were 2,770,000 yen and 2,599,000 yen) at $10.6 \mathrm{~km} / 1$ (25 MPG), the largest difference was 482,000 yen $(3,270,000$ yen and $3,752,000$ yen) at $23.4 \mathrm{~km} / 1$ (55 MPG). Although the difference of actual price between $10.6 \mathrm{~km} / 1$ (25 MPG) and $23.4 \mathrm{~km} / 1$ (55 MPG) was 500,000 yen, the difference of WTP between $10.6 \mathrm{~km} / 1$ (25 MPG) and $23.4 \mathrm{~km} / 1$ (55 MPG) was 1,150,000 yen. The results can also be explained by the misunderstanding (rather cognitive bias) that the larger change of $\mathrm{km} / \mathrm{l}(\mathrm{MOG})$ linearly leads to the larger reduction in gas consumption.

\section{Questionnaire3 - Comparison of Percentage Correct Choice between $\mathbf{k m} / \mathbf{l}$ and l//km Representation}

The results indicate that using $1 / \mathrm{km}$ instead of $\mathrm{km} / \mathrm{l}$ is effective for preventing people from being deceived by MPG illusion. The reason why the percentage choosing Option1 in Questionnaire3 was different between this study (42\%) and Larrick and Soll (2008) (25\%) is speculated as follows. While 171 participants in Larrick and Soll (2008) were drawn from a national subject pool, and their age ranged from 18 to 75 years old with a median age of 35, this study recruited 66 participants from students who major in engineering and are more accustomed to the treatment of calculation related to $\mathrm{km} / \mathrm{l}$.

These studies demonstrated that using $\mathrm{km} / \mathrm{l}$ (MPG) as a measure of fuel efficiency caused a systematic misunderstanding about the reduction in gas consumption. Relying on linear reasoning about $\mathrm{km} / \mathrm{l}$ (MPG), that is, expecting linear relationship between fuel efficiency and reduction of gas consumption leads people to misunderstand that an increase in fuel efficiency linearly leads to the reduction in gas consumption. This corresponds to linear-scaling error (bias).

The replacement of $\mathrm{km} / \mathrm{l}$ by $1 / \mathrm{km}$ is effective for deleting linear-scaling error (bias) as shown in Figure 2 . The finding by Larrick and Soll (2008) was verified in this study. In other words, expression as 1/km or GPM was found to be an effective debiasing method. Representing fuel efficiency in terms of volume-over-distance instead of distance-over-volume made the benefits of greater fuel efficiency more transparent.

\section{General Discussion}

The general finding is that there is no cross-cultural difference of MPG illusion between US and Japanese people. If the $21.3 \mathrm{~km} / 1$ (50 MPG) fuel efficiency is used as a standard of comparison, small improvements in $\mathrm{km} / 1$ (MPG) improvement from $6.8 \mathrm{~km} / 1$ (16 MPG) to $8.5 \mathrm{~km} / 1$ (20 MPG) look like leading to less reduction in gas consumption. Therefore, we tend to misunderstand that the reduction in gas consumption from $14.5 \mathrm{~km} / 1$ (34 MPG) to $21.3 \mathrm{~km} / 1$ (50 MPG) is larger than that from $6.8 \mathrm{~km} / 1$ (16 MPG) to $8.5 \mathrm{~km} / 1$ (20 MPG) (For detail, see Table 1). When translating fuel efficiency to gas consumption, we readily get trapped in MPG illusion and cannot think rationally. Consequently, the misunderstanding above occurs.

As pointed out in Section 4.3, the replacement of $\mathrm{km} / \mathrm{l}$ (MPG) by $1 / \mathrm{km}$ (GPM) is effective for mitigating the misunderstanding on the reduction of gas consumption, and participants tended to pay more attention to fuel economy information and choose fuel-efficient cars. Bazerman and Tenbrunsel (2013) also pointed out that changing the way in which information is presented works for the removal of cognitive bias. While they are using volume-over-distance measures such as $1 / \mathrm{km}$ or GPM to express fuel economy information in Europe, Canada, and Australia, US, Japan, and other countries have yet to correct distance-over-volume measures such as $\mathrm{km} / \mathrm{l}$ or MPG. This suggest that the format in which data is presented affects our decision making and potentially contributes to the removal of linear-scaling error (bias) such as MPG illusion. 
Framing effect (Kahneman, 2011) is a phenomenon that a different choice or decision is obtained from the same information depending on how the information is presented to a decision maker. When the measures are expressed with a positive frame like measures A (save 200 people) and B (save 600 people with a probability of one-third), it generally tends that a majority of people choose a certain alternative A. Although measures A and B are the same as measures C (force 400 people into death) and D (save all of 600 people with a probability of one-third, and force all people into death with a probability of two-thirds), respectively, we tend to choose measure $\mathrm{D}$ when the measures are presented to us using a negative frame. If we can think rationally and adopt a rational alternative, we should adopt measures $\mathrm{A}$ and $\mathrm{C}$ irrespective of the type of a frame (positive or negative). However, we cannot make a rational choice. In this manner, our choice is different depending on the type of a frame even if the same information is presented to us. This indicates that we should observe and see things or events from multiple viewpoints to avoid a cognitive bias caused by framing effect. The replacement of $\mathrm{km} / \mathrm{l}$ or MPG by $1 / \mathrm{km}$ or GPM is regarded as viewing from a different frame. While the measure $\mathrm{km} / \mathrm{l}$ or MPG is viewed from the frame of fuel efficiency, the measure $1 / \mathrm{km}$ or GPM is viewed from the frame of reduction of gas consumption. The approach from a different frame contributes to the removal of MPG illusion. In this study, it was verified that viewing from multiple perspectives is helpful for avoiding a cognitive bias.

Although Todd and Gigerenzer (2000), Gigerenze, Todd, and ABC Research Group (1999), and Gigerenzer and Goldstein (1996) showed that the simple (fast and frugal) heuristics perform comparably to complex and deliberate algorithms when fast and frugal heuristics by System1 lead to robustness of thinking processes, this is not necessarily true and such heuristic frequently causes cognitive biases. Larrick (2004) described the sources of biases in decision making. He classified debiasing strategies into motivational, cognitive, and technological ones. Cognitive strategies included "consider the opposite" and training in representations. Arkes (1991) also suggested that a few general causes underlie a wide range of cognitive biases, and that recognizing the causes of biases might facilitate predicting when some debiasing strategies would be dominant. The replacement of $\mathrm{km} / \mathrm{l}$ or MPG by $1 / \mathrm{km}$ or GPM corresponds to the way in which the information is represented and consideration of the opposite, which facilitates the identification of cognitive biases, and consequently contributes to avoiding cognitive biases.

The misunderstanding (linear-scaling error (bias)) of MPG has implications for environmental decision making. As expressing fuel efficiency as $\mathrm{km} / \mathrm{l}$ or MPG leads to such a cognitive bias (MPG illusion) and 1/km or GPM is effective for removing such a bias, it implies that expressing fuel efficiency as both volume-over-distance measure and distance-over-volume measure is helpful. Although distance-over-volume measures such as $\mathrm{km} / \mathrm{l}$ or MPG is useful for estimating the range of a car's gas tank, $1 / \mathrm{km}$ or GPM allows us to understand exactly how much gas we are using in a given interval. Volume-over-distance measures also make the calculation of cost savings from reduced gas consumption easier.

\section{Conclusions}

The current work has focused on the MPG illusion, meaning that we mistake the curvilinear relationship between MPG and fuel efficiency with linear relationship. The results can be summarized as follows:

(1) The participants misunderstood that the larger change of $\mathrm{km} / \mathrm{l}$ linearly led to the larger reduction in gas consumption.

(2) The perceived relationship between km/l (MPG) and WTP (Willingness to Pay) was linear, while the actual relationship was curvilinear. 
(3) The MPG illusion was observed for both US and Japanese people, and no cross cultural difference was detected concerning this type of cognitive bias.

(4) The MPG illusion (bias) was effectively removed by replacing distance-over-volume measures such as $\mathrm{km} / \mathrm{l}$ or MPG by volume-over-distance measures such as $1 / \mathrm{km}$ or GPM.

\section{References}

Altman, M. A. (2012). Behavioral economics for dummies. John Wiley \& Sons Canada, Ltd..

Angner, E. (2012). A course in behavioral economics. Palgrave Macmillan.

Arkes, H. R. (1991). Costs and benefits of judgment errors: Implications for debiasing. Psychological Bulletin, 110, 486-498, 1991.

Bazerman, M. H., \& Moore, D. A. (2001). Judgment in managerial decision making. Harvard University Press.

Bazerman, M. H., \& Tenbrunsel, A. E. (2011). Blind spot. Princeton, N.J.: Princeton University Press.

Dobelli, R. (2013). The art of thinking clearly. NewYork, N.Y.: Harper.

Gigerenzer, G., \& Goldstein, D. G. (1996). Reasoning the fast and frugal way: Models of bounded rationality. Psychological Review, 103, 650-669.

Gigerenzer, G., Todd, P. M., \& the ABC Research Group. (1999). Simple heuristics that make us smart. Oxford University Press.

Kahneman, D., \& Tversky, A. (1984). Choices, values, and frames. American Psychologist, 39(4), 341-350.

Kahneman, D. (2011). Thinking, Fast and Slow. Penguin Books.

Larrick, R. P. (2004). Debiasing, In D. K. Koehler, \& N. Harvey (Eds.), Blackwell handbook of judgment \& decision (pp. 316-337). Blackwell Publishing.

Larrick, R. P., \& Soll, J. B. (2008). The MPG illusion. Science, 320, 1593-1594.

Murata, A., Nakamura, T., \& Kubo, S. (2014). Basic study on prevention of human error-Debiasing method of cognitive biases in decision making. Proc. of AHFE 2014, 126-135.

Murata, A., Nakamura, T., \& Karwowski, W. (2015). Influence of cognitive biases in distorting decision making and leading to critical unfavorable incidents. Safety, 1(1), 44-58.

Todd, P. M., \& Gigerenzer, G. (2000). Precis of simple heuristics that makes us smart. Behavioral and Brain Sciences, 23, 727-780.

Tversky, A., \& Kahneman, D. (1974). Judgment under uncertainty: Heuristics and biases. Science, 185, 1124-1131.

Tversky, A., \& Kahneman, D. (1983). Extensional versus intuitive reasoning: The conjunction fallacy in probability judgment. Psychological Review, 90, 293-315. 